\title{
Comparative toxicogenomics of three insensitive munitions constituents 2,4- dinitroanisole, nitroguanidine and nitrotriazolone in the soil nematode Caenorhabditis elegans
}

Ping Gong ${ }^{1 *}$, Keri B. Donohue ${ }^{1}$, Anne M. Mayo ${ }^{1}$, Yuping Wang ${ }^{2}$, Huixiao Hong ${ }^{2}$, Mitchell S. Wilbanks', Natalie D. Barker ${ }^{3}$, Xin Guan ${ }^{3}$ and Kurt A. Gust ${ }^{1}$

\begin{abstract}
Background: Ecotoxicological studies on the insensitive munitions formulation IMX-101 and its components 2,4-dinitroanisole (DNAN), nitroguanidine (NQ) and nitrotriazolone (NTO) in various organisms showed that DNAN was the main contributor to the overall toxicity of IMX-101 and suggested that the three compounds acted independently. These results motivated this toxicogenomics study to discern toxicological mechanisms for these compounds at the molecular level.

Methods: Here we used the soil nematode Caenorhabditis elegans, a well-characterized genomics model, as the test organism and a species-specific, transcriptome-wide $44 \mathrm{~K}$-oligo probe microarray for gene expression analysis. In addition to the control treatment, C. elegans were exposed for $24 \mathrm{~h}$ to 6 concentrations of DNAN (1.95-62.5 ppm) or NQ (83-2667 ppm) or 5 concentrations of NTO (187-3000 ppm) with ten replicates per treatment. The nematodes were transferred to a clean environment after exposure. Reproduction endpoints (egg and larvae counts) were measured at three time points (i.e., 24-, 48- and 72-h). Gene expression profiling was performed immediately after 24-h exposure to each chemical at the lowest, medium and highest concentrations plus the control with four replicates per treatment.

Results: Statistical analyses indicated that chemical treatment did not significantly affect nematode reproduction but did induce 2175, 378, and 118 differentially expressed genes (DEGs) in NQ-, DNAN-, and NTO-treated nematodes, respectively. Bioinformatic analysis indicated that the three compounds shared both DEGs and DEG-mapped Reactome pathways. Gene set enrichment analysis further demonstrated that DNAN and NTO significantly altered 12 and 6 KEGG pathways, separately, with three pathways in common. NTO mainly affected carbohydrate, amino acid and xenobiotics metabolism while DNAN disrupted protein processing, $A B C$ transporters and several signal transduction pathways. NQ-induced DEGs were mapped to a wide variety of metabolism, cell cycle, immune system and extracellular matrix organization pathways.

(Continued on next page)
\end{abstract}

\footnotetext{
* Correspondence: ping.gong@usace.army.mil

${ }^{1}$ Environmental Laboratory, U.S. Army Engineer Research and Development

Center, 3909 Halls Ferry Road, Vicksburg, MS 39180, USA

Full list of author information is available at the end of the article
}

(c) The Author(s). 2018 Open Access This article is distributed under the terms of the Creative Commons Attribution 4.0 International License (http://creativecommons.org/licenses/by/4.0/), which permits unrestricted use, distribution, and reproduction in any medium, provided you give appropriate credit to the original author(s) and the source, provide a link to the Creative Commons license, and indicate if changes were made. The Creative Commons Public Domain Dedication waiver (http://creativecommons.org/publicdomain/zero/1.0/) applies to the data made available in this article, unless otherwise stated. 
(Continued from previous page)

Conclusion: Despite the absence of significant effects on apical reproduction endpoints, DNAN, NTO and NQ caused significant alterations in gene expression and pathways at 1.95 ppm, 187 ppm and 83 ppm, respectively. This study provided supporting evidence that the three chemicals may exert independent toxicity by acting on distinct molecular targets and pathways.

Keywords: Toxicogenomics, Acute toxicity, Caenorhabditis elegans, Insensitive munitions, Microarray, Differentially expressed genes, Gene set enrichment analysis (GSEA), Kyoto Encyclopedia of Genes and Genomes (KEGG) pathways,

\section{Background}

The history of insensitive munitions (IMs) can be traced back to June 1978 when the U.S. Department of Defense (DoD) and Department of Energy (DOE) agreed to undertake a joint effort to study the utility of insensitive high explosives and propellants in some typical DoD conventional weapons systems $[1,2]$. Unlike conventional ordnance, IMs are not prone to detonate due to shock, heat or fire, and hence enhances the safety of occupational workers and soldiers during manufacturing, transportation, storage, and use for testing, training and military operations [2]. In 2010, the U.S. Army approved IMX-101 (an acronym for Insensitive Munitions Explosive 101) as the first IM formulation, which passed all six criteria, i.e., fragment impact, shaped charge jet impact, slow cook-off, fast cook-off, multiple bullets into high explosives, and sympathetic detonation [3].

To fully characterize the potential human health and environmental risks associated with exposure to IMX-101, many toxicological and ecotoxicological studies have been conducted with IMX-101 and its three constituents: 2,4-dinitroanisole (DNAN, replacing 2,4,6-trinitrotoluene or TNT), 3-Nitro-1,2,4-Triazol-5-One (NTO, replacing 1,3,5-trinitro-1,3,5-triazacyclohexane also known as Research Department formula X or RDX), and nitroguanidine (NQ) (see Fig. 1 for their chemical structures). In vivo (including acute, subacute, and subchronic exposures) and in vitro toxicity testing results suggest that DNAN [4] has moderate toxicity whereas NQ [5] and NTO [6] have no or low toxicity to a wide variety of physiological, histopathological, reproductive, developmental, genotoxicity, and mutagenicity endpoints in mammalian rodents such as rats, mice and rabbits. In a 14-day subacute toxicity study, DNAN caused anemia and hepatocellular injury in female rats and hyperalbuminemia in male rats [7]. In another 90-day subchronic study, oral gavage of DNAN led to mortality at the highest dose $(80 \mathrm{mg} / \mathrm{kg} /$ day $)$, and other sublethal effects including altered neuromuscular functions (neurotoxicity), anemia, splenic enlargement, hemosiderosis and extramedullary hematopoiesis (all of which indicated blood as a target organ), as well as testicular toxicity manifested as decreased mass of testes and epididymides, seminiferous tubule degeneration and epididymal aspermia in males [7]. A single administration of 120 and $150 \mathrm{mg}$
DNAN/kg caused mortality in 2-week old male Japanese quails (1/5 and 5/9 dosed quails, respectively) and cataracts in all of the surviving quails [8]. Another study suggests that DNAN can induce maternal reproductive toxicity, embryo toxicity and fetus teratogenicity in pregnant rats dosed with 5,15 and $45 \mathrm{mg} / \mathrm{kg} / \mathrm{d}$ for 2 weeks during gestation [9]. The primary effect of concern for NTO is testicular toxicity observed in rats and mice in both subchronic and extended one-generation reproductive toxicity tests [10-13]. NTO does not exhibit estrogenic or antiandrogenic endocrine disrupting [14] or neurobehavioral [10] effects in rats at doses up to $1000 \mathrm{mg} / \mathrm{kg} / \mathrm{d}$. Reddy et al. [15] revealed that NTO was not genotoxic using a battery of in vitro and in vivo genotoxicity tests. The low toxicity of NTO may be attributed to its low electron-accepting property as demonstrated by its reaction with both single-electron and two-electron transferring flavoenzymes [16].

Ecotoxicological assessment of the three IM constituents has been mostly performed in aquatic organisms. DNAN severely inhibited methanogens, nitrifying bacteria, and Aliivibrio fischeri with $50 \%$ inhibitory concentrations $\left(\mathrm{IC}_{50}\right)$ ranging 41-57 $\mu \mathrm{M}$ but was notably less inhibitory to aerobic heterotrophs $\left(\mathrm{IC}_{50}>390 \mu \mathrm{M}\right)$ [17]. Dodard et al. [18] observed the following ecotoxicity for DNAN: $50 \%$ effect concentrations $\left(\mathrm{EC}_{50}\right)$ of $4.0 \mathrm{mg} / \mathrm{L}$ for $72-\mathrm{h}$ Pseudokirchneriella subcapitata (green alga) growth, $7 \mathrm{mg} / \mathrm{kg}$ for 19-d Lolium perenne (ryegrass) growth, $60.3 \mathrm{mg} / \mathrm{L}$ for 30-min A. fischeri bacteria bioluminescence, and $31 \mathrm{mg} / \mathrm{kg}$ for 48-h Eisenia andrei (earthworm) soil avoidance, and a 14-d 50\% lethal concentration $\left(\mathrm{LC}_{50}\right)$ of $47 \mathrm{mg} / \mathrm{kg}$ for $E$. andrei. DNAN induced DNA damages in Daphnia carinata with a $48-\mathrm{h} \mathrm{LC}_{50}$ of $15 \mathrm{mg} / \mathrm{L}$ derived from a comet assay [19]. Kennedy et al. [20] reported acute and chronic toxicity of DNAN to Pimephales promelas (fathead minnow) and two cladocerans (Ceriodaphnia dubia and Daphnia pulex): acute $\mathrm{LC}_{50}$ ranging from $14.2 \mathrm{mg} / \mathrm{L}$ to $42 \mathrm{mg} / \mathrm{L}$, chronic $\mathrm{LC}_{50} 10 \mathrm{mg} / \mathrm{L}$ to $>24.2 \mathrm{mg} / \mathrm{L}$, and reproductive $\mathrm{IC}_{50} 2.7 \mathrm{mg} / \mathrm{L}$ to $10.6 \mathrm{mg} / \mathrm{L}$, with $D$. pulex being the most sensitive species. Using Rana pipiens (leopard frog) tadpoles as the test organism, Stanley et al. [21] observed a $96-\mathrm{h} \mathrm{LC}_{50}$ of $24.3 \mathrm{mg} / \mathrm{L}$ for DNAN and a $28-\mathrm{d}$ mortality LOEC (lowest observable effect concentration) of $2.4 \mathrm{mg} / \mathrm{L}$ and $5.0 \mathrm{mg} / \mathrm{L}$ for DNAN and NTO, respectively. However, neither tadpole developmental stage nor growth 


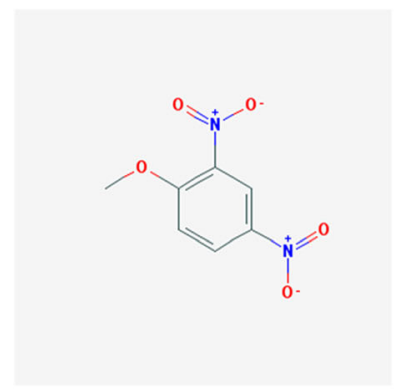

2,4-Dinitroanisole (DNAN)

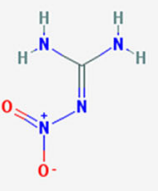

Nitroguanidine (NQ)

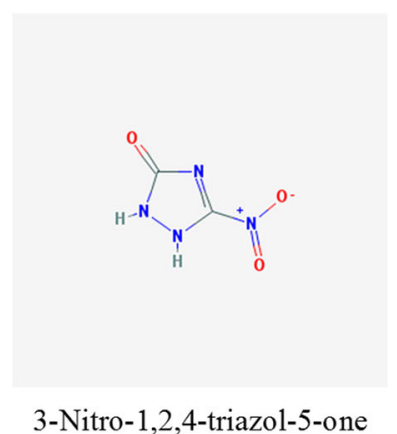

(NTO)

Fig. 1 The 2D structures of three IMX-101 constituents

was significantly affected in any of the 28-d exposures [21]. NQ has low acute toxicity to fish including rainbow trout (Ongorhynchus myisi), fathead minnows, channel catfish (Ictalurus punctatus), and bluegills (Lepomis macrochirus), invertebrates including water fleas (Daphnia magna), amphipods (Hyallela azteca and Gammarus minus), midge larvae (Paratanytarsus dissimilis), and aquatic worms (Lumbriculus variegatus), and algae (Selenastrum capricornutum) up to the water solubility limit level [22]. Chronic toxicity data of NQ show the non-observable adverse effect level (NOAEL) $260 \mathrm{mg} / \mathrm{L}$ and lowest observable adverse effect level (LOAEL) $440 \mathrm{mg} / \mathrm{L}$ in C. dubia [23], the LOEC $2030 \mathrm{mg} / \mathrm{L}$ and no observable effect concentration (NOEC) $1050 \mathrm{mg} / \mathrm{L}$ (based on early life stage reduction in total length) in fathead minnows [23], and not toxic to rainbow trout up to saturation [22, 23].

Other data from ongoing investigations in our laboratory suggest that DNAN, NTO and NQ elicited independent toxicity to test organisms including fathead minnow larvae [24], the fresh-water amphipod Hyallela azteca (Lotufo et al. Unpublished data) and the earthworm Eisenia fetida (Gong et al. Unpublished data). In agreement with published results, our data also indicated that DNAN and NTO account for the majority of toxicity exerted by IMX-101 with DNAN being more toxic than NTO. Nevertheless, mode-of-action results for the three IM constituents are only now beginning to emerge, e.g., in fish species $[24,25]$, but a significant knowledge gap remains. In order to fill this knowledge gap, we launched the present toxicogenomics study to investigate the toxicological mechanisms of IM constituents, where we hypothesized that the three chemicals would act independently on different molecular targets and affect different biological pathways in Caenorhabditis elegans. C. elegans was chosen as the test organism because toxicity testing in this organism can bridge genetic, biochemical, developmental and physiological endpoints [26]. In addition, C. elegans is a free-living organism with a small $(1 \mathrm{~mm}$ in length) and transparent body, a fully described developmental program, and a short life cycle [27]. Of importance for genomics studies, it has a completely sequenced (ca. $100 \mathrm{Mb}$ ) and well-annotated (20,362 protein coding and 24,719 non-coding genes) genome ([28]; also see http://useast.ensembl.org/Caenorhabditis_elegans/Info/Annotation).

There is increasing evidence that toxicity testing results obtained using C. elegans are predictive of outcomes in higher eukaryotes including humans, likely due to genetic conservation and physiological similarity [29]. For instance, $90 \%$ of human lysosome associated non-disease genes and 70\% of human lysosomal storage disorder genes have C. elegans homologs [30], allowing for rapid screening of lysosomal toxins using C. elegans in vivo assays [31]. In addition, good correlation was reported for metal salts between C. elegans lethality ranking and mammalian oral $\mathrm{LD}_{50}$ ranking [32, 33]. All these features make $C$. elegans an excellent toxicogenomics model for identification of molecular targets as well as rapid risk assessment of uncharacterized chemicals $[26,29]$ including IM compounds.

\section{Methods}

Animal culturing and preparation

The wild-type $C$. elegans var. Bristol, strain N2, was maintained at $20{ }^{\circ} \mathrm{C}$ on NGM (Nematode Growth Media) agar plates seeded with Escherichia coli OP50 bacteria according to standard protocols [34, 35]. The culture was synchronized at the first larval stage (L1) by bleaching with a $5 \%$ sodium hypochlorite solution $[35,36]$. Worms were harvested by gentle rinsing with $\mathrm{K}$ Medium in late L3 stage which were determined by both length and age $[27,37]$. Worms of larval stage L3 were used in 24-h acute exposures to ensure that worms would not reach the egg-laying adult age within the time period of exposure, thus eliminating the confounding effect of RNA from laid or unlaid eggs being incorporated into genomic analysis. After harvesting from agar plates, worms were spun at $1150 \times \mathrm{g}$ for $2.5 \mathrm{~min}$ and re-suspended in a given volume of 
K Medium [36]. Twenty $\mu \mathrm{L}$ of worms were deposited on a microscope slide with a grid, and all the worms in the grid were counted. The number of worms $/ \mathrm{mL}$ was then calculated. Wide-bore pipet tips or transfer pipets were always used to avoid shearing of worms.

\section{Acute exposure}

Worms in late L3 stage were used for acute toxicity testing [37]. Three sets of experiments were performed: viability, reproduction and gene expression, where worms were exposed in tissue-culture treated (TC) plates for $24 \mathrm{~h}$ to DNAN, NTO, or NQ [38]. All test solutions were prepared in $\mathrm{K}$ medium except that acetone was used to dissolve DNAN, resulting in 5\% carrier in the final solution. In addition to the vehicle or blank controls, the viability assay tested at least 5 concentrations per compound with 3 replicates per concentration. The nominal concentrations in viability assays were: vehicle control (VC), 1.95, 3.91, 7.81, 15.6, 31.2, 62.5, 125, 250, 500 and $1000 \mathrm{mg}$ DNAN/L, blank control (BC), 187.5, 375, 750, 1500 and $3000 \mathrm{mg} \mathrm{NTO/L}$, and BC, $93.75,187.5,375,750$ and $1500 \mathrm{mg} \mathrm{NQ} / \mathrm{L}$. Those in reproduction assays were: $\mathrm{VC}, 1.95,3.91,7.81,15.6,31.2$, $62.5 \mathrm{mg}$ DNAN/L, BC, 187.5, 375, 750, 1500, $3000 \mathrm{mg}$ NTO/L, and BC, 83, 167, 333, 666, 1333, $2667 \mathrm{mg}$ NQ/ L. Those in the genomics study were: VC, 1.9, 15.5, $62 \mathrm{mg}$ DNAN/L, BC, 187, 750, $3000 \mathrm{mg} \mathrm{NTO/L}$, and $\mathrm{BC}, 83,666,2667 \mathrm{mg} \mathrm{NQ} / \mathrm{L}$. For viability and reproduction studies, 96-well TC plates were used with ca. 30 worms housed in a well and each well was filled with $100 \mu \mathrm{l}$ of $\mathrm{K}$ medium or chemical-amended solution. For gene expression studies, 24-well TC plates were used with 400 worms per well and each well was filled with $1 \mathrm{ml}$ of $\mathrm{K}$ medium or test solution. Each treatment in the reproduction and genomics studies had 5 replicates.

\section{Viability and reproduction experiments}

In both experiments, prior to and immediately after exposure, dead and live worms in each well were confirmed and counted. After exposure, six surviving worms from each well in the reproduction study (30 worms in total) were transferred to an agar plate for rinsing to remove test chemical. Then, each rinsed worm was placed in a new well containing $100 \mu \mathrm{l}$ of $\mathrm{K}$ medium and $E$. coli OP50 bacteria at an optical density (OD) of 0.2 , and allowed to reproduce. At 24, 48 and $72 \mathrm{~h}$, plates were fixed with a $5 \%$ final volume of paraformaldehyde and stored at $4{ }^{\circ} \mathrm{C}$. At each time point, 10 wells per treatment were examined. Offspring, including laid eggs and larvae, were counted and any mortality of adults was also recorded [37]. Statistical analysis of viability and reproduction data (i.e., analysis of variance or ANOVA) was performed using the AOV function in $\mathrm{R}$ (version 3.3.1).

\section{Microarray design}

Global gene expression was analyzed using a custom-designed Agilent $C$. elegans-specific microarray that contained 42,862 probes targeting 28,164 unique genes, among which $76.6 \%$ or 21,562 genes had a single probe, $23.4 \%$ or 6596 genes had 2 to 12 probes, and the remaining 6 genes had 13, 15, 20, 26, 27 and 37 probes, respectively. These probes were assembled from three existing Agilent probe groups: PGRID51529TDT (512 probes), PGRID51764TDT (50), and PGRID51763TDT (42300). These 60-mer oligo probes, together with 1319 control probes, were printed in situ on a 364-row by 164-column array grid in an 8-array-per-slide format, yielding a $70 \%$ occupancy of 62,976 available spots. This custom-commercial hybrid array was deposited in the Gene Expression Omnibus (GEO) repository as platform GPL22795 (https://www.ncbi.nlm.nih.gov/ geo/query/acc.cgi?acc $=$ GPL22795).

\section{Microarray experiment}

After the 24-h exposure, all 400 worms per well were collected into a cryogenic vial and spun at $1150 \times \mathrm{g}$ for $2.5 \mathrm{~min}$. Supernatant was removed and the vial were flash frozen in liquid nitrogen and stored at $-80{ }^{\circ} \mathrm{C}$. Total RNA was extracted from each vial using RNeasy mini kits (Qiagen, Valencia, CA) and treated as one biological replicate. Four of the five replicates (total RNA samples) per treatment were chosen for further microarray hybridization. One hundred ng of total RNA was first reverse-transcribed into cDNA, followed by cDNA labeling using Low Input Quick Amp Labeling Kits (Agilent, Palo Alto, CA) in the presence of cyanine 3-CTP dye. The labeled cDNA was hybridized to the $C$. elegans-specific $44 \mathrm{~K}$-olig array (one sample/array) at $65{ }^{\circ} \mathrm{C}$ for $17 \mathrm{~h}$ using Agilent's Gene Expression Hybridization Kits [39]. A total of 48 samples (3 chemicals $\times 4$ treatments per chemical $\times 4$ replicates per treatment) were randomly assigned and hybridized to six $8 \times 60$ K-array slides containing $44 \mathrm{~K}$ oligonucleotide probes per array.

\section{Gene expression data analysis}

An Agilent high-resolution DNA Microarray Scanner Model G2565CA was used to scan microarray images (resolution $=2 \mu \mathrm{m}$ per pixel). Raw microarray gene expression data were extracted from acquired array images as spot and background signal intensity using Agilent's Feature Extraction software v10.7. A spot was flagged out if its raw signal intensity was below its background level, or if it was saturated. A gene was flagged out if over $50 \%$ of the 48 samples had missing values for this gene. The filtered data was background subtracted and log-transformed. The spike-in RNA mix with known composition and RNA copy numbers was used to 
construct standard linear regression curves, from which the unknown worm RNA concentrations were derived. The derived RNA concentrations were normalized to the median value per array (sample). The raw and normalized array data were deposited in the GEO database as series GSE92365 (https://www.ncbi.nlm.nih.gov/geo/ query/acc.cgi?acc=GSE92365). Multivariate permutation tests with random variance model implemented in BRB-Array Tools version 4.5 [40] were performed to infer differentially expressed genes (DEGs). One thousand random permutations were computed per chemical class (i.e., a group of 16 arrays or samples). The confidence level of false discovery rate assessment was set at $80 \%$, and the maximum allowed portion of false-positive genes was $10 \%$.

\section{Pathway analysis}

Pathway mapping was conducted to map DEGs to computationally inferred C. elegans pathways in the Reactome Knowledgebase Version 56 (www.reactome.org; [41]). Gene set enrichment analysis (GSEA) [42] was performed to derive KEGG (Kyoto Encyclopedia of Genes and Genomes) pathways (www.genome.jp/kegg/; [43]) statistically enriched with DEGs. A GSEA v3.0 beta 2 desktop application was downloaded from http://software.broadinstitute.org/gsea/downloads.jsp.

Reactome and KEGG contain both manually curated and computationally inferred biological pathways which are updated regularly. For example, KEGG releases 1-2 new pathway maps every month and constantly updates existing maps [43]. In the current study, we downloaded the V56 Reactome and the then-most-updated KEGG pathways released in or before June 2016. There were 134 KEGG pathways and 1434 Reactome pathways computationally inferred for C. elegans from their orthologous reference pathways in model organisms such as humans, mice, rats and fruit flies, which were manually curated. Hence, the findings reported here should be regarded as those derived and interpreted using the best knowledge available at the time of the study.

Pathways in Reactome are organized hierarchically, following the gene ontology (GO) biological process hierarchy [41]. At the highest hierarchical level, there are 26 groups of pathways such as cell cycle, cell-cell communication, developmental biology, DNA repair and replication, DNA and protein metabolism, immune system, muscle contraction, reproduction and signal transduction. Unlike Reactome, KEGG assigns genes molecular level functions defined in > 20,000 KEGG Orthology (KO) entries, which are mapped to six categories of manually drawn regular KEGG reference pathway maps, including 160 metabolism, 22 genetic information processing, 38 environmental information processing, 24 cellular processes, 78 organismal systems and 81 human diseases pathways [43].

\section{Results}

\section{Acute toxicity of DNAN, NTO and NQ to C. elegans}

No statistically significant effects of NTO and NQ were observed on the survival of L3-stage worms in the acute 24-h exposures (data not shown). However, DNAN caused significant mortality $(p<0.01$, ANOVA with Tukey's honest significance test)

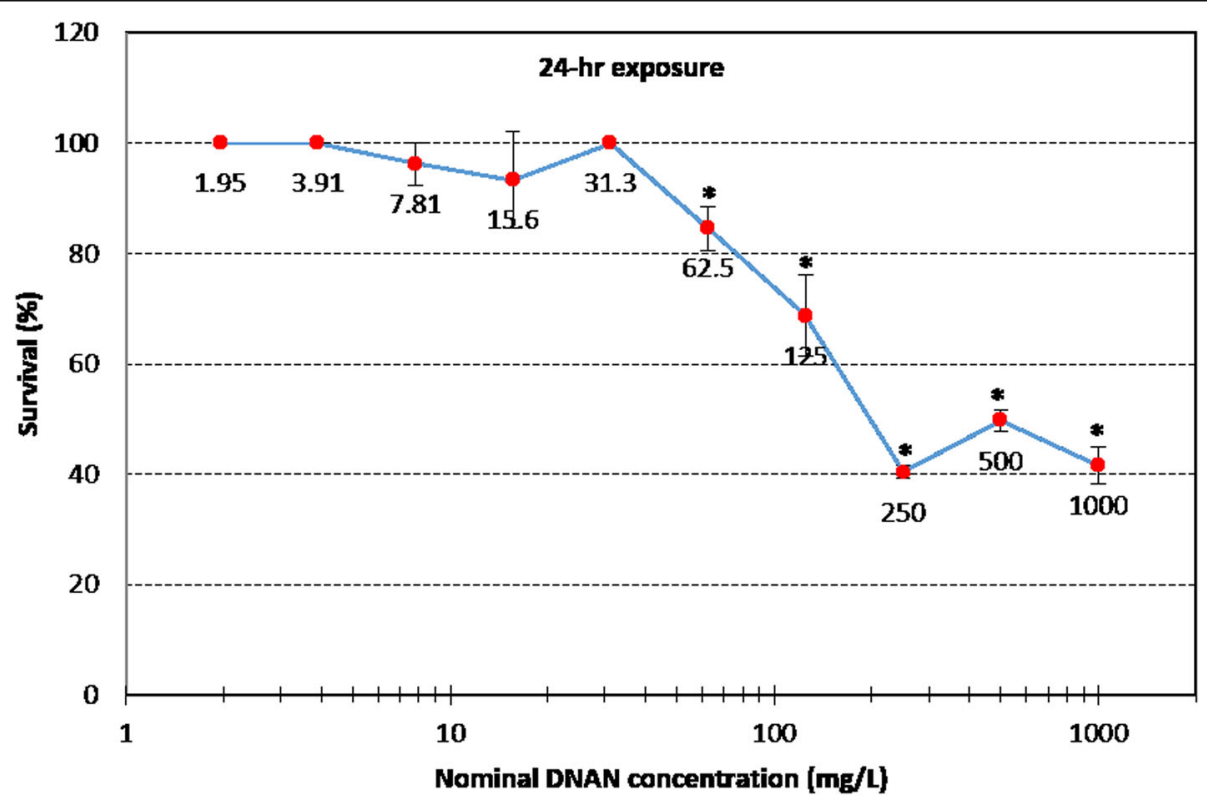

Fig. 2 Effects of 24-h exposure to DNAN on C. elegans viability ( $n=3$ with each replicate having ca. 30 worms, error bar = standard deviation). "*" represents statistical significance between treatment and control at $p<0.01$ (ANOVA with Tukey's honest significance test) 


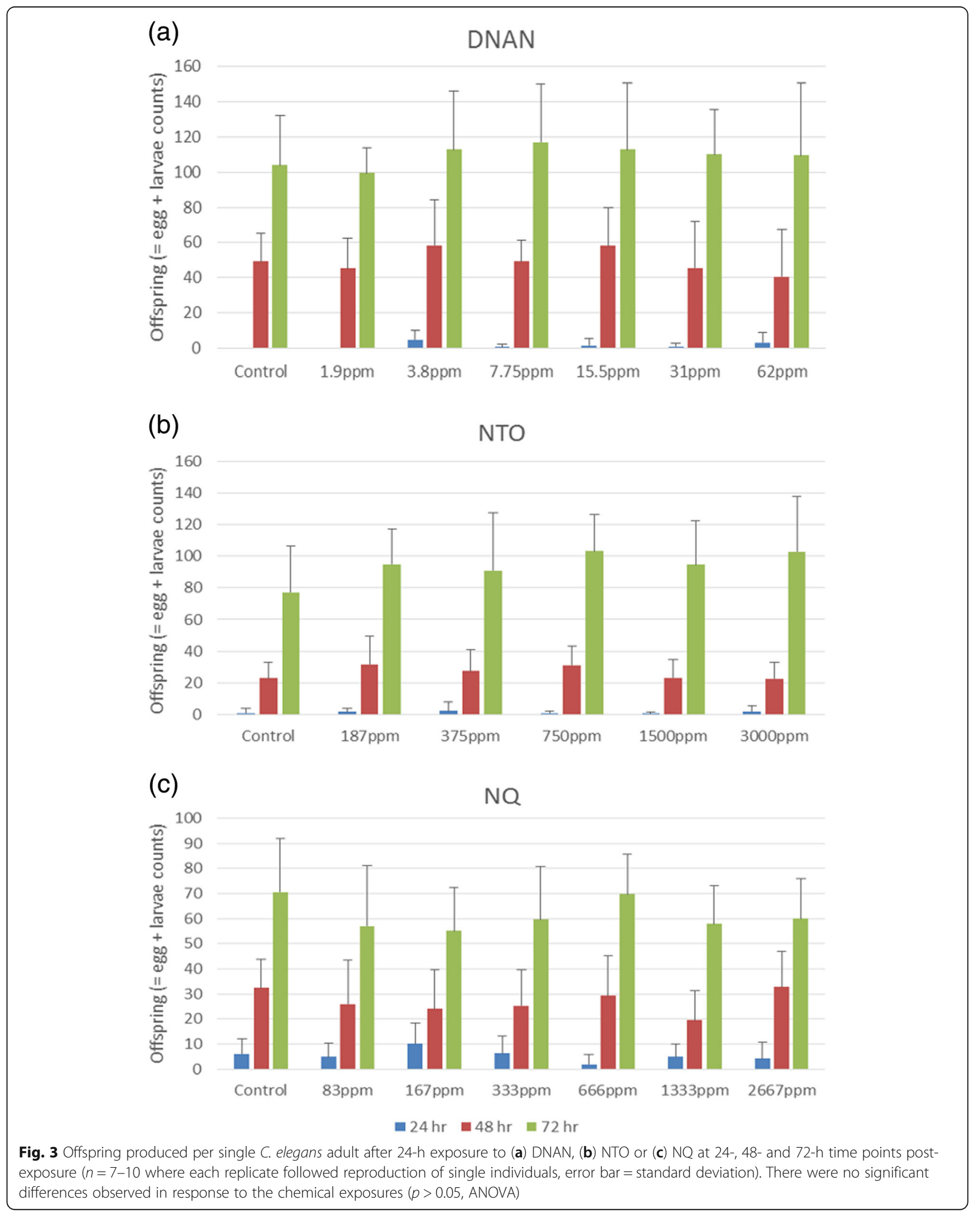


reducing survivorship by nearly $60 \%$ in the $250 \mathrm{mg} /$ L exposure (Fig. 2) with a LOEC of $62.5 \mathrm{mg}$ DNAN/L in the $C$. elegans acute exposure. Regarding the reproduction endpoints, acute exposure to the three compounds at non-lethal concentrations, i.e., $1.9-62.5 \mathrm{mg}$ DNAN/L, 187-3000 mg NTO/L, or 83-2667 mg NQ/L, did not significantly affect offspring production (i.e., egg or larvae counts and the sum of both) at any of the three time points, i.e., 24-, 48-, and 72-h post exposure (Fig. 3). Statistical comparisons of the controls for the DNAN, NTO and NQ experiments showed no significant difference $(p>0.05$, ANOVA) at each of the three time points, demonstrating consistent performance of the C. elegans across the three toxicity tests. The reason why the $62.5 \mathrm{mg}$ DNAN/L treatment caused mortality but no reproductive toxicity was likely due to the fact that only surviving worm were used in the reproductive assays. These acute toxicity testing results are consistent with reported toxicity for these compounds in other organisms.

\section{Sublethal transcriptional effects}

Initial filtering of the 48-array gene expression dataset removed 117 C. elegans probes (due to the missing of more than $50 \%$ values across arrays). Then the remaining 42,745 probes were collapsed to 28,104 unique genes as multiple probes/probe sets were reduced to one per gene symbol by using maximally expressed probe/probe set measured by average intensity across arrays. Gene expression effects were determined at 1.9, 15.5, $62.5 \mathrm{mg}$ DNAN/L, 187, 750, $3000 \mathrm{mg} \mathrm{NTO} / \mathrm{L}$, or 83, 666, $2667 \mathrm{mg} \mathrm{NQ} / \mathrm{L}$, in comparison with respective controls. The total number of non-redundant DEGs of the three groups is 2489 .
Statistical analyses indicated that 2175, 378, and 118 DEGs were affected in NQ-, DNAN-, and NTO-treated nematodes, respectively, with only 11 DEGs shared by all three groups (Fig. 4 and Additional file 1). On the other hand, $60 \%$ of DEGs in response to NTO were common with DEGs responding to either NQ or DNAN. Further, 36\% of the DEGs in response to DNAN were common with DEGs in response to either NQ or NTO. This result suggests that the three compounds acted on both common and different gene targets.

A breakdown of the DEGs by exposure concentration and regulation pattern shows that the number of both up- and down-regulated DEGs increased with concentration for all three compounds (Fig. 5). Persistently, more DEGs were up-regulated than down-regulated across all compounds and all concentrations. The proportion of consistently up- or down-regulated DEGs at all three concentrations for each compound was small, i.e., $<6 \%$ of the total DEGs for each compound, except that 51 of the 52 DEGs up-regulated at $187 \mathrm{mg} \mathrm{NTO} / \mathrm{L}$ were also up-regulated at the two higher NTO concentrations. However, DEGs highly overlapped between the two higher concentrations, i.e., $88 \%$ to $100 \%$ of the DEGs affected at the medium concentration were also affected at the highest concentration.

\section{Bioinformatics analysis of DEGs and affected Reactome/ KEGG pathways}

The KEGG gene symbols of the 2489 unique DEGs were first converted to their equivalent UniProt gene identifier using a file linking KEGG Genes to UniProt (a)

\section{All DEGs}

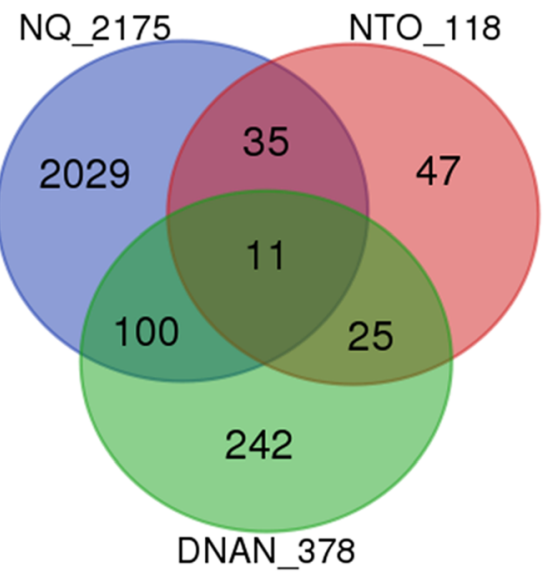

(b)

DEGs matched with UniProt ID

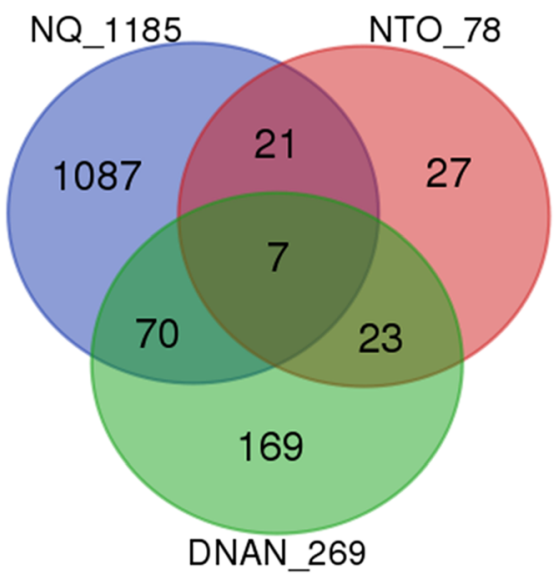

Fig. 4 Overlapping of (a) differentially expressed genes (DEGs) inferred from DNAN, NTO, and NQ treatments as well as (b) of those DEGs matched with a UniProt identifier 


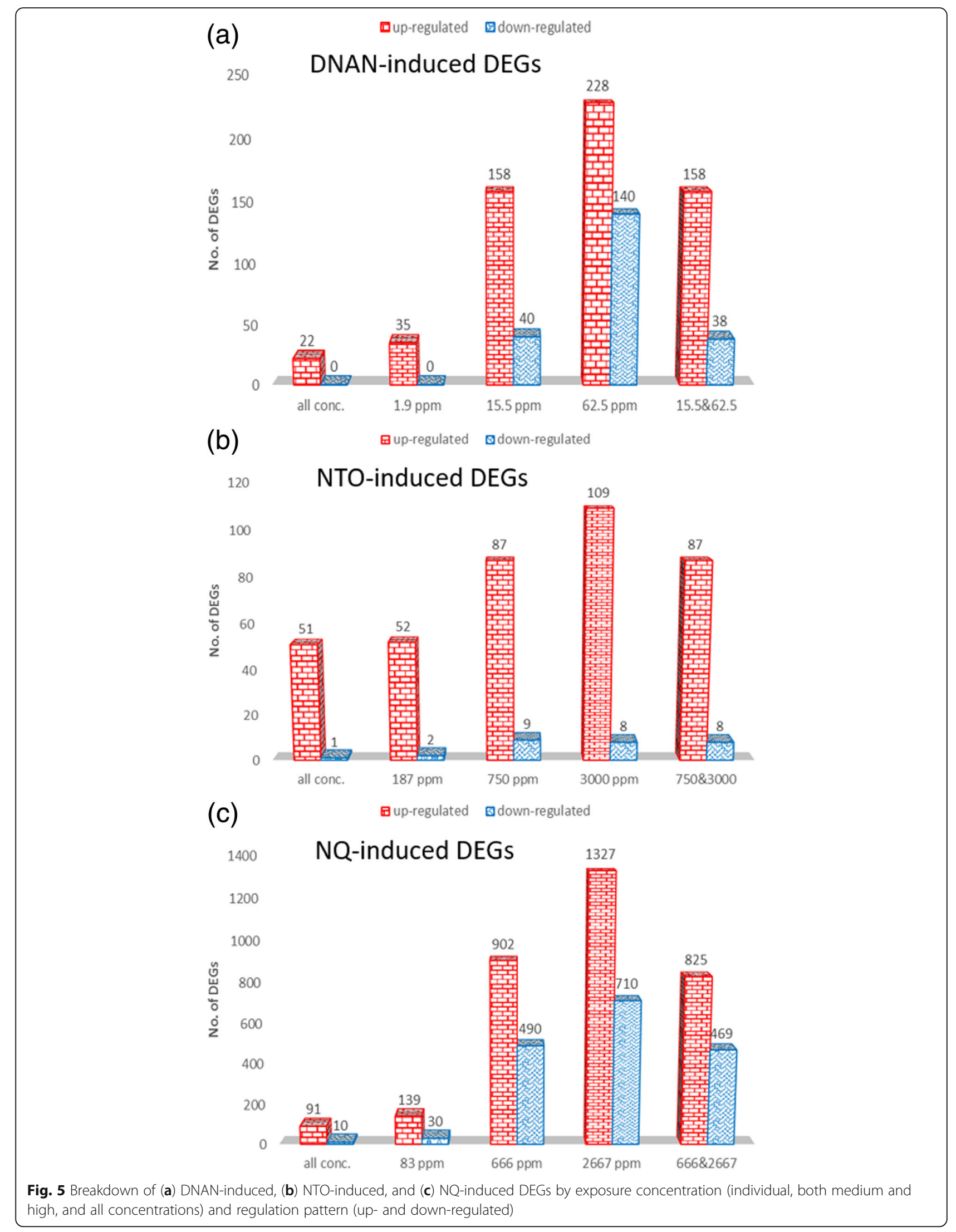


(Additional file 2), which was downloaded from KEGG LinkDB (http://www.genome.jp/linkdb/). As a result, 1185, 269 and 78 NQ-, DNAN-, and NTO-affected DEGs, respectively, were matched with UniProt gene identifiers (Additional file 2). Then, these UniProt gene identifiers (1404 non-redundant) were mapped to the lowest hierarchical level of C. elegans-specific Reactome pathways using a UniProt-to-Pathways mapping file (Additional file 3), which was downloaded from the Reactome pathway database (http://www.reactome.org/ pages/download-data/). The following mapping results were obtained: 127 NQ-affected, 30 DNAN-affected, and 14 NTO-affected DEGs were mapped to 165,30 , and 22 Reactome pathways, respectively (Tables 1 and 2; Additional file 3). Up to 15 unique DEGs were mapped to a single pathway (Table 3), and a single DEG was mapped to as many as 10 pathways (Additional file 3). When pathways mapped with 1 to 3 DEGs were removed, there left only 17, 10 and 2 pathways mapped with NQ-, DNAN, and NTO-affected DEGs, respectively (Table 3). The overlapping of all DEG-mapped pathways and those mapped with more than three DEGs are shown in Fig. 6.

To prepare for GSEA, we first mapped nearly 50\% (13512) of the probed genes (i.e., genes represented on the microarray) to 134 KEGG-curated C. elegans biological pathways (www.kegg.jp) (see Additional file 4 for details). Additional file 4 was uploaded as the gene set file for GSEA analysis together with an expression dataset (relevant sample array data from GSE92365), a phenotype label (e.g., control 1/2/3/4 and DNAN_1.9 ppm 1/2/3/4) file and a chip annotation (i.e., gene symbols in GPL22795) file. GSEA results of these mapped KEGG pathways (see examples of GSEA output files in Fig. 7) revealed that DNAN and NTO affected 12 and 6 pathways, respectively, with 3 in common (Table 4). Although NQ had the highest amount of DEGs, no enriched pathway was statistically significant (False Discovery Rate or FDR $<0.25$ and significant at 2 or 3 concentrations).

\section{Discussion}

At exposure concentrations having no significant effects on lethality and reproduction (except for $62.5 \mathrm{mg}$ DNAN/L), we observed significant impacts in acute response to each of the three IM constituents on transcriptome-wide gene expression. Our study provided evidence that transcriptomic effects were concentrationdependent with the lowest exposure concentration significantly altering gene expression, i.e., $1.95 \mathrm{ppm}$, $187 \mathrm{ppm}$ and $83 \mathrm{ppm}$ for DNAN, NTO and NQ, respectively (Fig. 4). Findings from the comparative toxicogenomic analyses suggest that the three chemicals shared some common target genes and pathways but also acted independently on different genes and pathways (Figs 4, 5 and 6). In the following, we focus
Table 1 Statistics of differentially expressed genes (DEGs) mapped to the lowest hierarchical level of Reactome pathways: Breakdown of DEGs by the number of pathways that a DEG is mapped to. Blank cells indicate zero DEG or pathway. See Additional file 3 for the detailed listings of mapped DEGs and pathways

\begin{tabular}{llrl}
\hline $\begin{array}{l}\text { Number of } \\
\text { pathways/DEG }\end{array}$ & \multicolumn{2}{l}{ Number DEGs affected by } \\
\cline { 2 - 4 } & DNAN & NTO & NQ \\
\hline 1 & 8 & 3 & 59 \\
2 & 6 & 9 & 30 \\
3 & 1 & & 13 \\
4 & 1 & 7 \\
5 & & 3 \\
6 & & 5 \\
7 & & 2 & 1 \\
10 & 14 & 14 & 9 \\
Sum & 30 & & 127 \\
\hline
\end{tabular}

our discussion on the altered pathways identified using two different approaches.

Our pathway mapping analysis (Table 3 and Figs. 8 and 9) suggests that NQ affected one Reactome pathway (with $\geq 4$ mapped DEGs) each within the cell cycle, extracellular matrix organization and immune system groups, in addition to 12 Reactome metabolism pathways. NTO and DNAN only affected 2 and 10 Reactome metabolism pathways, respectively. All pathways affected by DNAN were also altered by NQ. However, NTO did not share any altered pathways with NQ or DNAN. Interestingly, eicosanoids and synthesis of prostaglandins

Table 2 Statistics of differentially expressed genes (DEGs) mapped to the lowest hierarchical level of Reactome pathways: Breakdown of pathways by the number of DEGs mapped to a single pathway. Blank cells indicate zero DEG or pathway. See Additional file 3 for the detailed listings of mapped DEGs and pathways

\begin{tabular}{lccc}
\hline $\begin{array}{l}\text { Number of } \\
\text { DEGs/pathway }\end{array}$ & \multicolumn{3}{l}{ Number of pathways affected by } \\
\cline { 2 - 4 } & DNAN & NTO & NQ \\
\hline 1 & 17 & 13 & 102 \\
2 & 3 & 2 & 30 \\
3 & & & 2 \\
4 & & 2 \\
5 & & 3 \\
6 & & & 8 \\
8 & 9 & & 2 \\
9 & 1 & & \\
14 & 30 & 22 & 165 \\
15 & & & \\
Sum & & & \\
\hline
\end{tabular}


Table 3 Reactome pathways mapped by four or more DEGs induced by NQ, NTO, or DNAN

\begin{tabular}{|c|c|c|c|c|}
\hline Pathway ID & Pathway name & NQ & NTO & DNAN \\
\hline R-CEL-211979 & Eicosanoids & & $4^{a}$ & \\
\hline R-CEL-2162123 & Synthesis of Prostaglandins (PG) and Thromboxanes (TX) & & 4 & \\
\hline R-CEL-1660662 & Glycosphingolipid metabolism & 4 & & \\
\hline R-CEL-2046106 & Alpha-linolenic acid (ALA) metabolism & 4 & & \\
\hline R-CEL-193368 & Synthesis of bile acids and bile salts via 7alpha-hydroxycholesterol & 5 & & \\
\hline R-CEL-75105 & Fatty Acyl-CoA Biosynthesis & 5 & & \\
\hline R-CEL-1442490 & Collagen degradation & 6 & & \\
\hline R-CEL-1679131 & Trafficking and processing of endosomal toll-like receptor (TLR) & 6 & & \\
\hline R-CEL-187577 & Skp, Cullin, F-box protein containing complex (SCF)-Skp2-mediated degradation of p27/p21 & 6 & & \\
\hline R-CEL-156581 & Methylation & 8 & & 15 \\
\hline R-CEL-193048 & Androgen biosynthesis & 8 & & 14 \\
\hline R-CEL-193993 & Mineralocorticoid biosynthesis & 8 & & 14 \\
\hline R-CEL-194002 & Glucocorticoid biosynthesis & 8 & & 14 \\
\hline R-CEL-211957 & Aromatic amines can be N-hydroxylated or N-dealkylated by CYP1A2 & 8 & & 14 \\
\hline R-CEL-211981 & Xenobiotics & 8 & & 14 \\
\hline R-CEL-2142816 & Synthesis of (16-20)-hydroxyeicosatetraenoic acids (HETE) & 8 & & 14 \\
\hline R-CEL-5423646 & Aflatoxin activation and detoxification & 8 & & 14 \\
\hline R-CEL-211976 & Endogenous sterols & 9 & & 14 \\
\hline R-CEL-2142670 & Synthesis of epoxy (EET) and dihydroxyeicosatrienoic acids (DHET) & 9 & & 14 \\
\hline
\end{tabular}

${ }^{\mathrm{a}}$ Number of DEGs mapped to the pathway

(PGs) and thromboxanes (TXs), the two pathways affected by NTO, are categorized into cytochrome P450 and fatty acid synthesis, respectively. They are interconnected because PGs and TXs are collectively known as eicosanoids. Specifically, eicosanoids are synthesized primarily from arachidonic acid that is released from membrane phospholipids [44]. Once released, arachidonic acid is acted on by prostaglandin $\mathrm{G} / \mathrm{H}$ synthases (PTGS, also known as cyclooxygenases (COX)) to form PGs and TXs, by arachidonate lipoxygenases (ALOX)
[45]. Altered eicosanoids (PGs and TXs) biosynthesis may lead to aberrant regulation of immunopathological processes ranging from inflammatory responses to cancer and autoimmune disorder [44].

Our GSEA results (Table 4 and Fig. 10) indicate that DNAN and NTO both significantly affected KEGG pathways of carbohydrate, amino acid and xenobiotics metabolism, while DNAN also affected genetic and environmental information processing pathways. Interestingly, no pathway was significantly altered by NQ even though (a)

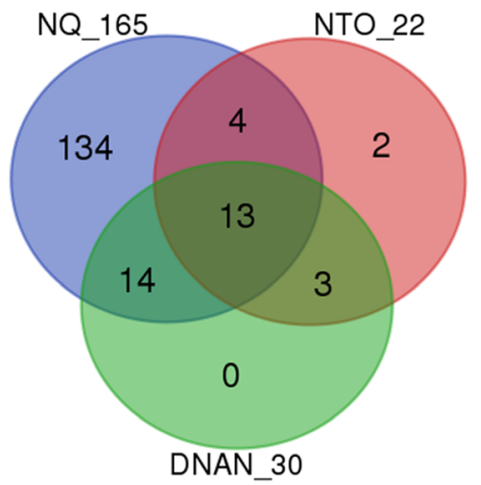

(b)

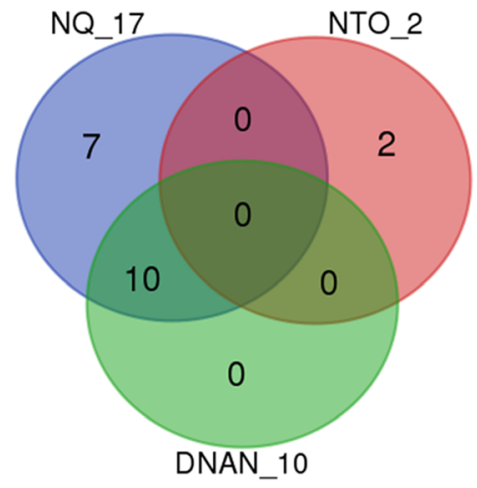

Fig. 6 Overlapping of computationally inferred C. elegans pathways in the Reactome database mapped by differentially expressed genes (DEGs). a All DEG-mapped pathways; b Pathways mapped with 4 or more DEGs. See Additional file 3 for the list of all DEG-mapped pathways and DEGs mapped to these pathways 


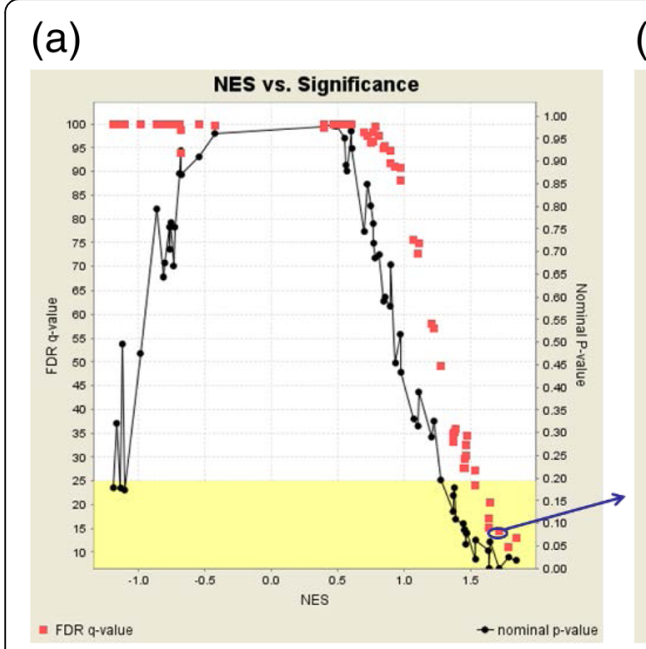

\section{(b)}

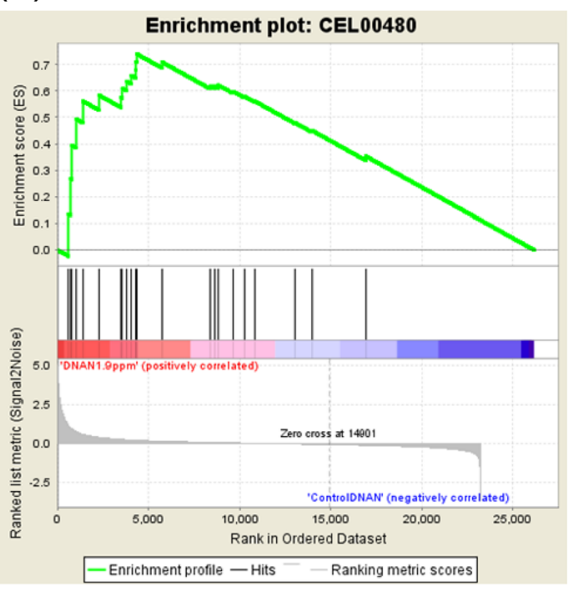

(c)

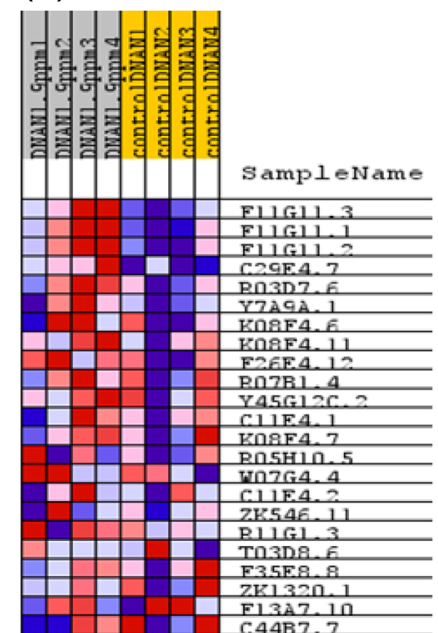

Fig. 7 Some examples of gene set enrichment analysis (GSEA) output files: a Normalized enrichment score (NES) plotted against false discovery rate (FDR) or nominal $P$-value which were derived from GSEA of 134 gene sets (i.e., KEGG pathways, see Additional file 4) in the Control vs. DNAN_1.9 ppm comparison; $\mathbf{b}$ Enrich plot of one of the gene set CEL00480 (FDR $=0.14$, see the blue circle and arrow in (a)) significantly altered by DNAN_1.9 ppm; and c Microarray gene expression heat map of the 23 genes mapped to the KEGG pathway CEL00480

NQ-induced DEGs can be mapped to multiple pathways. This was in agreement with the no apical toxicity of NQ up to the highest test concentration (Fig. 3c). It may be hypothesized that NQ does not possess any specific toxicity target but elicit general stress causing adaptive responses in exposed worms.

In contrast to NQ, NTO and DNAN acted on fewer but more specific biomacromolecular targets (Tables 1 and 2), leading to alterations of statistically significant pathways (Table 4). We may hypothesize that NTO and DNAN act independently due to the identified distinct pathways affected by DNAN only, including protein processing, $\mathrm{ABC}$ transporter and multiple signal transduction pathways (Table 4 and Fig. 10).

Results from these two analyses should be considered complementary. The differences in the results obtained from the pathway mapping and the GSEA analyses were largely due to the aforementioned differences between the two pathway databases (Reactome vs. KEGG) as well as the different approaches used (mapping vs. statistics). Despite such differences, there also exists commonality between the two analyses, i.e., xenobiotics metabolism by

Table 4 Significantly affected KEGG pathways derived using GSEA (FDR $<0.25$ at 2 or 3 concentrations)

\begin{tabular}{lllll}
\hline Pathway ID & Size & DNAN conc. & NTO conc. & KEGG pathway name \\
\hline CEL00350 & 15 & $15.5 ; 62.5$ & & Tyrosine metabolism \\
CEL00380 & 14 & & $750 ; 3000$ & Tryptophan metabolism \\
CEL00480 & 23 & $1.9 ; 15.5 ; 62.5$ & $187 ; 750 ; 3000$ & Glutathione metabolism \\
CEL00500 & 14 & $15.5 ; 62.5$ & & Starch and sucrose metabolism \\
CEL00630 & 14 & & Glyoxylate and dicarboxylate metabolism \\
CEL00830 & 10 & $15.5 ; 62.5$ & & Retinol metabolism \\
CEL00980 & 25 & $15.5 ; 62.5$ & $187 ; 750 ; 3000$ & Metabolism of xenobiotics by cytochrome P450 \\
CEL00982 & 27 & $15.5 ; 62.5$ & $187 ; 750 ; 3000$ & Drug metabolism - cytochrome P450 \\
CEL00983 & 17 & $15.5 ; 62.5$ & & Drug metabolism - other enzymes \\
CEL01200 & 25 & & Carbon metabolism \\
CEL02010 & 12 & $15.5 ; 62.5$ & & ATP-binding cassette (ABC) transporters \\
CEL04070 & 16 & $1.9 ; 15.5$ & & Phosphatidylinositol signaling system \\
CEL04141 & 60 & $1.9 ; 62.5$ & & Protein processing in endoplasmic reticulum \\
CEL04310 & 34 & $1.9 ; 62.5$ & Wnt signaling pathway \\
CEL04350 & 24 & $1.9 ; 62.5$ & Transforming growth factor beta (TGF $\beta$ ) signaling pathway
\end{tabular}




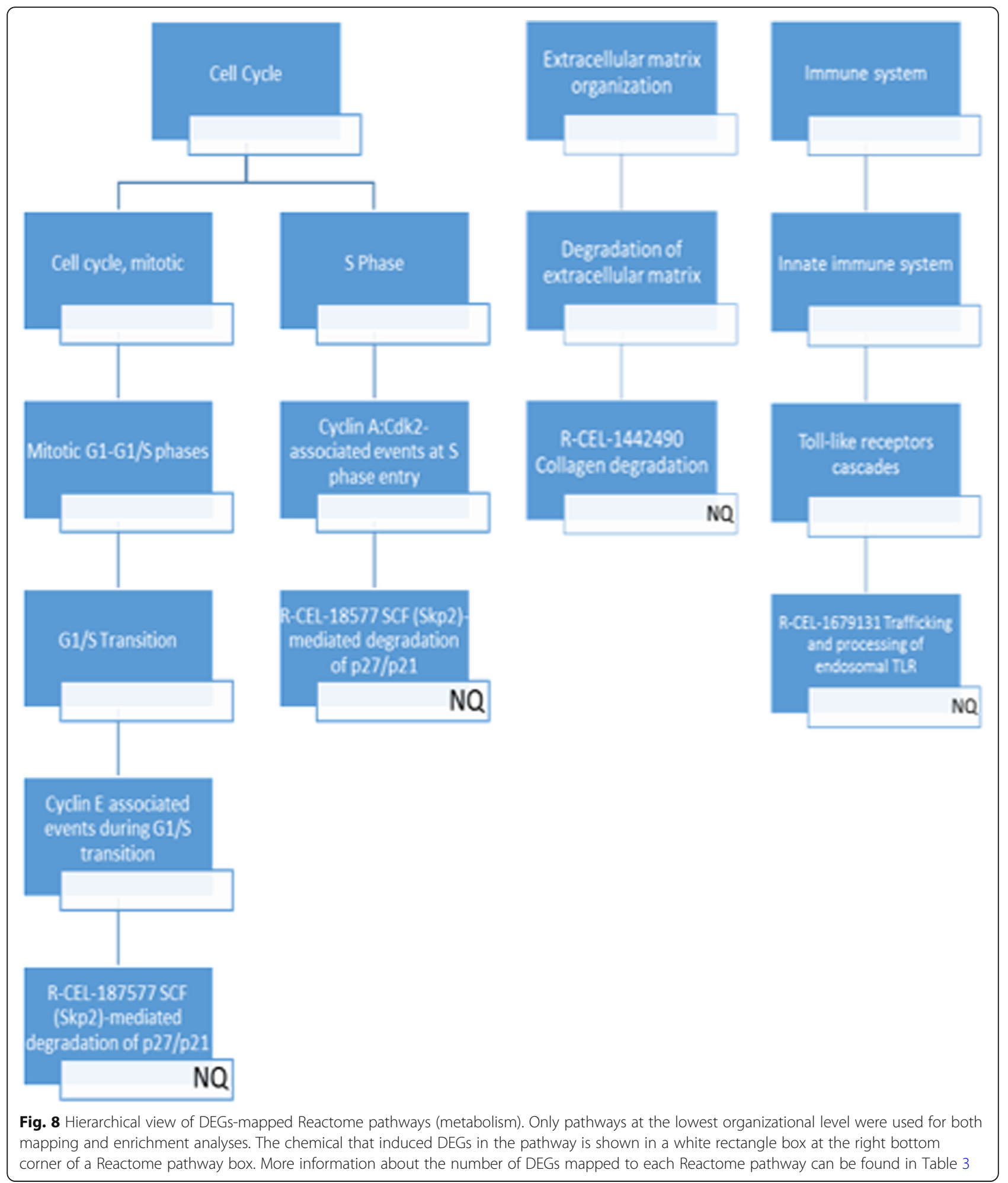

cytochrome P450 (R-CEL-211981 in Table 3 and CEL00 980 in Table 4). This suggests that exposure to NQ, DNAN or NTO can all induce the Phase I biotransformation of xenobiotic toxicants mediated by the $\mathrm{P} 450$ isozyme system [46].
A primary goal of toxicogenomics research is to identify novel biomarkers and elucidate mode of toxicological action. Findings from our previous earthworm toxicogenomics studies indicate that TNT mainly acts as a reactive oxidative stressor affecting a variety of 


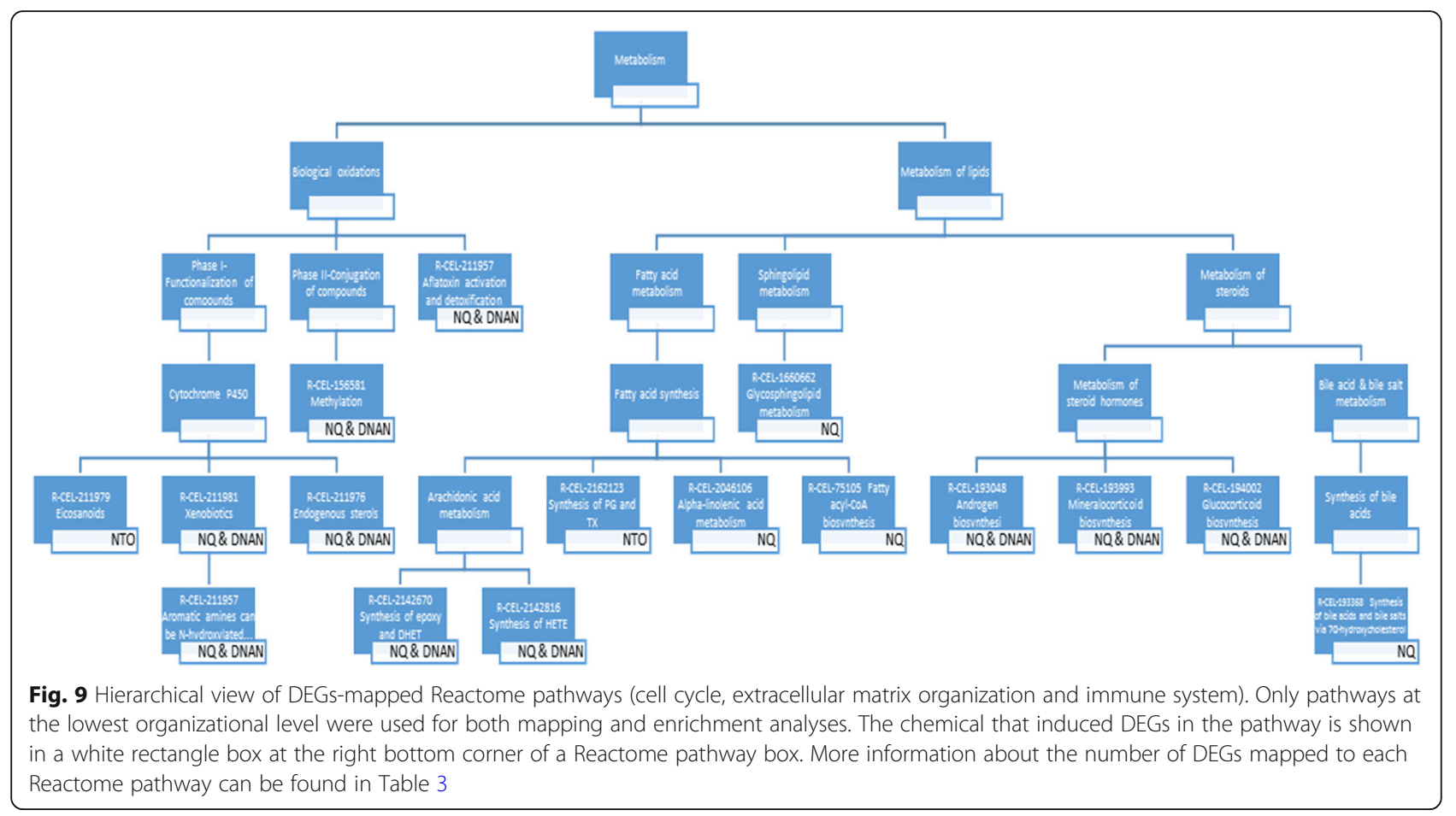

biological processes such as muscle contraction, fibrinolysis and coagulation, iron homeostasis, and innate immunity [47, 48]. Our further functional assays confirmed chitinase activity and methemoglobinemia-like blood disorder as specific biomarkers in TNT-exposed earthworms [48]. Similarly, RDX was found to primarily cause neurotoxicity and reproductive toxicity by affecting neuronal signaling (cholinergic and GABAergic synapses) pathways and spermatogenesis [49-52]. Electrophysiological assays and reproductive toxicity tests confirmed both neurotoxicity and reproductive toxicity of $\mathrm{RDX}[49,52,53]$. Compared with TNT and RDX, we just began a long journey of unveiling the toxicological mechanisms for IM constituents. Although significant transcriptomic effects were observed for all three IM constituents at concentrations that do not cause any lethal or reproductive effects, we ought to carry out more functional assays and measure biochemical, physiological and enzymatic endpoints to discern adaptive and reversible responses or hormesis from permanent and irreversible damages.

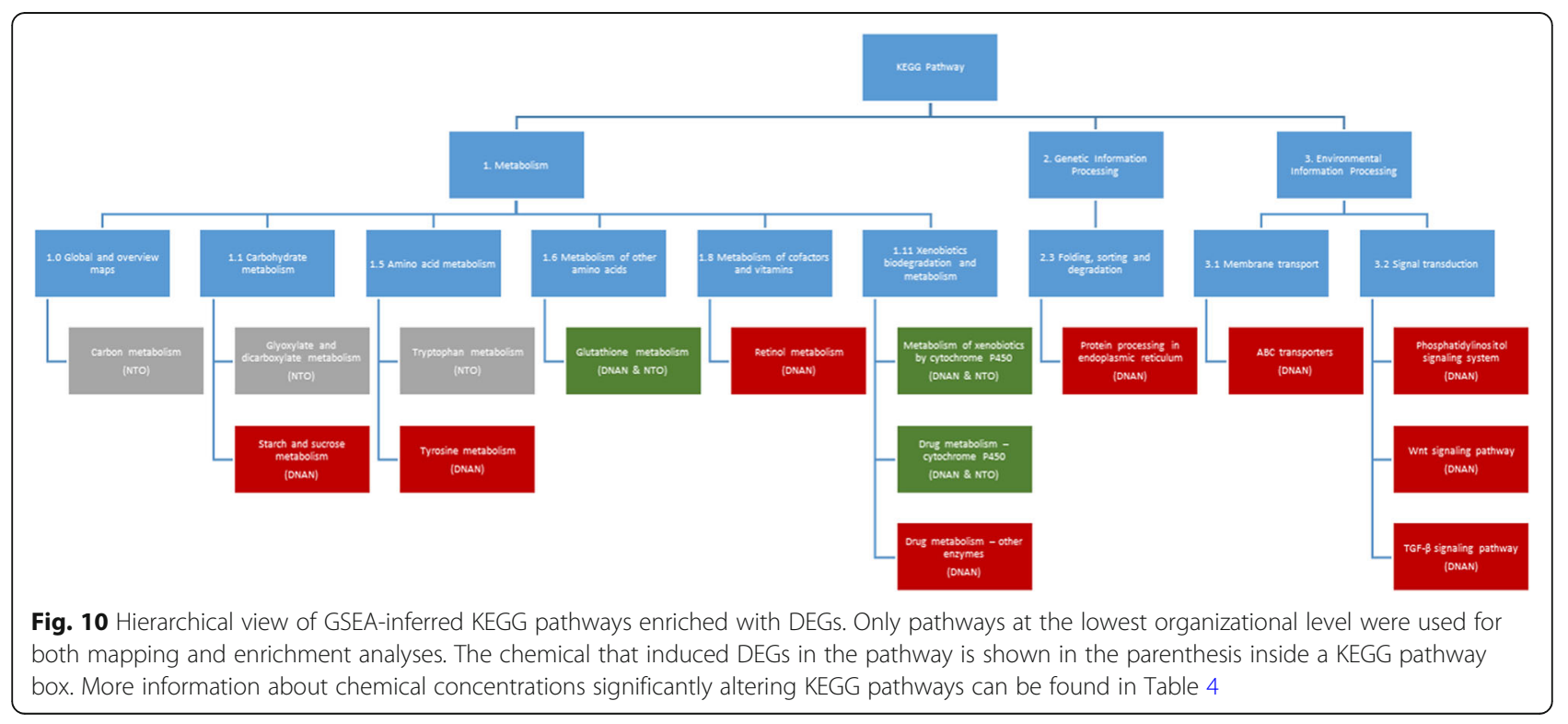


A number of ecotoxicological studies have demonstrated that DNAN has a significantly lower toxicity than such legacy explosives as TNT and RDX in such animal models as water fleas and fish [19, 20], earthworms [18], and frog tadpoles [21]. These results suggest that IMs may pose less environmental risks than legacy explosives. This study investigated the parent form of the three IM constituents without considering their possible biotransformation products (e.g., [54-56]). Further studies are warranted to tease apart the contribution of these breakdown products to the adverse effects reflected in the bioassays designed to measure the parent compounds. In addition, toxicogenomic studies need to be conducted for legacy explosives such as TNT and RDX using the same $C$. elegans model in order to better differentiate their modes of toxicological action from those of IM compounds. It should also be noted that microarray-based toxicogenomic studies often serve as preliminary evidence to generate hypotheses for in-depth and confirmative research into toxicological mechanisms. Such research may be conducted using $C$. elegans genetic mutant strains. For instance, Liao et al. [57] employed a chemotaxis assay [58] to identify the neuronal location of olfactory receptors responding to explosives-associated volatiles.

\section{Conclusions}

This comparative toxicogenomics study demonstrated that at individual concentrations not causing significant reduction in nematode reproduction, DNAN, NQ and NTO induced 378, 2175 and 118 DEGs in exposed nematodes, respectively. The three compounds shared both DEGs and DEG-mapped Reactome pathways. GSEA results suggest that DNAN and NTO significantly altered 12 and 6 KEGG pathways, separately, with three pathways in common. NTO mainly affected carbohydrate, amino acid and xenobiotics metabolism, DNAN disrupted protein processing, $\mathrm{ABC}$ transporters and several signal transduction pathways, and NQ-induced DEGs were mapped to a wide variety of metabolism, cell cycle, immune system and extracellular matrix organization pathways. Taken together, this study provided supporting evidence that the three chemicals, if mixed (e.g., in IMX-101), may exert independent toxicity by acting on distinct molecular targets and pathways.

\section{Additional files}

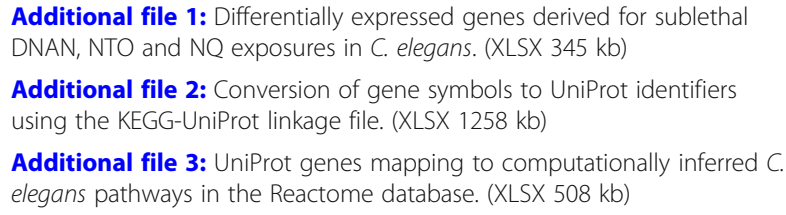

Additional file 4: Gene set file (i.e., gene mapping to KEGG-curated C. elegans pathways) used for gene set enrichment analysis (GSEA). (XLSX $31694 \mathrm{~kb})$

\section{Abbreviations}

ALOX: Arachidonate lipoxygenases; BC: Blank control; COX: Cyclooxygenases; DEG: Differentially expressed gene; DNAN: 2,4-dinitroanisole;

DoD: Department of Defense; DOE: Department of Energy; $\mathrm{EC}_{50}$ : 50\% effective concentration; FDR: False discovery rate; GEO: Gene expression omnibus; GO: Gene ontology; GSEA: Gene set enrichment analysis; IC 50: $_{50 \%}$ inhibitory concentration; IM: Insensitive munition; IMX-101: Insensitive munitions explosive 101; KEGG: Kyoto Encyclopedia of Genes and Genomes; KO: KEGG orthology; LC 50: 50\% lethal concentration; LOAEL: Lowest observable adverse effect level; NES: Normalized enrichment score; NGM: Nematode growth media; NOAEL: Non-observable adverse effect level; NOEC: No observable effect concentration; NQ: Nitroguanidine; NTO: 3-Nitro1,2,4-triazol-5-one; OD: Optical density; PG: Prostaglandin;

PTGS: Prostaglandin G/H synthases; RDX: Research Department formula X; TC: Tissue-culture; TNT: 2,4,6-trinitrotoluene; TX: Thromboxanes; VC: Vehicle control

\section{Acknowledgements}

The wild-type C. elegans strain N2 used in this work was provided by Caenorhabditis Genetics Center (CGC), which is funded by National Institutes of Health (NIH) Office of Research Infrastructure Programs (P40 OD010440). We thank three anonymous peer-reviewers and three internal reviewers from the U.S. Army Program Executive Office Ammunition (PEO Ammo) and U.S. Army Armament Research, Development and Engineering Center (ARDEC) for their critical comments. Permission was granted by the Chief Engineer of U.S. Army Corps of Engineers to publish this paper.

\section{Funding}

This work was supported by an intramural grant awarded by the U.S. Army Environmental Quality and Installation Program. Publication of this article was also funded by the grant.

\section{Availability of data and materials}

All data generated or analyzed during this study are included in this published article and its Additional files. The raw and normalized microarray data were deposited in GEO as series GSE92365 (https:// www.ncbi.n/m.nih.gov/geo/query/acc.cgi?acc=GSE92365).

\section{Disclaimer}

The content is solely the responsibility of the authors and does not necessarily represent the official views of U.S. Army Corps of Engineers and U.S. Food and Drug Administration.

\section{About this supplement}

This article has been published as part of BMC Systems Biology Volume 12 Supplement 7, 2018: From Genomics to Systems Biology. The full contents of the supplement are available online at https://

bmcsystbiol.biomedcentral.com/articles/supplements/volume-12supplement-7.

\section{Authors' contributions}

This study was conceived by KAG, KBD and PG. KBD and AMM maintained the $C$. elegans culture and conducted the acute exposure and reproduction toxicity tests. MSW, NDB and XG performed microarray experiments. PG, YW, $\mathrm{HH}, \mathrm{KBD}$ and $\mathrm{AMM}$ analyzed the data. $\mathrm{PG}$ and $\mathrm{AMM}$ drafted the manuscript. $K A G, P G, M S W, K B D$ and $A M M$ revised the manuscript. All authors reviewed the revised manuscript and approved the final manuscript.

Ethics approval and consent to participate

Not applicable.

Consent for publication

Not applicable.

Competing interests

The authors declare that they have no competing interests. 


\section{Publisher's Note}

Springer Nature remains neutral with regard to jurisdictional claims in published maps and institutional affiliations.

\section{Author details}

${ }^{1}$ Environmental Laboratory, U.S. Army Engineer Research and Development Center, 3909 Halls Ferry Road, Vicksburg, MS 39180, USA. Division of Bioinformatics and Biostatistics, National Center for Toxicological Research, U.S. Food and Drug Administration, Jefferson, AR 72079, USA. ${ }^{3}$ Bennett Aerospace Inc., 1249 Kildaire Farm Road, Cary, NC 27511, USA.

\section{Published: 14 December 2018}

\section{References}

1. Spear RJ, Davis LM. 1989. An Australian insensitive munitions policy: a working paper prepared for the Australian Ordnance Council. Report No. MRL-GD-0020, Victoria, Australia.

2. Beauregard RL. 2011. The history of insensitive munitions. Retrieved from http://www.insensitivemunitions.org/ on December 6, 2017.

3. Picatinny Public Affairs. 2010. Army approves safer explosives to replace TNT. Retrieved from https://www.army.mil/article/43553 on December 6, 2017

4. TERA (Toxicology Excellence for Risk Assessment). 2014a. Occupational Alliance for Risk Science (OARS) Workplace Environmental Exposure Level (WEEL) for 2,4-Dinitroanisole (DNAN). Retrieved at http://www.tera.org/ OARS/DNAN\%200ARS\%20WEEL\%20Public\%20Comment.pdf on December 6. 2017.

5. Sample B, Arenal CA, Reinke EN, Reddy G. Wildlife toxicity assessment for nitroguanidine. In: Williams M, Reddy G, Quinn M, Johnson MS, editors. Wildlife toxicity assessments for Chemicals of Military Concern. Amsterdam: Elsevier; 2015. p. 147-60.

6. TERA (Toxicology Excellence for Risk Assessment). 2014b. Occupational Alliance for Risk Science (OARS) Workplace Environmental Exposure Level (WEEL) for 3-Nitro-1,2,4-Triazole-5-One. Retrieved at http://www.tera.org/ OARS/NTO\%200ARS\%20WEEL \%20Public\%20Comment.pdf on December 6. 2017

7. Lent EM, Crouse LC, Wallace SM. Oral toxicity of 2,4-dinitroanisole in rats. Int J Toxicol. 2016a;35(6):692-711.

8. Takahashi KW, Saito TR, Amao H, Kosaka T, Obata M, Umeda M, Shirasu Y. Acute reversible cataract due to nitro-compounds in Japanese quail (Coturnix coturnix japonica). Jikken Dobutsu. 1988;37(3):239-43.

9. Gao J, Zhang P, Liu Z, Wang H, Yue H, Lu Q, Dang J. Study of embryonic toxicity and teratogenicity of 2, 4-dinitroanisole in rats. Chin J Ind Hyg Occup Dis. 2016:34(1):50-2.

10. Crouse LC, Lent EM, Leach GJ. Oral toxicity of 3-nitro-1,2,4-triazol-5-one in rats. Int J Toxicol. 2015;34(1):55-66.

11. Lent EM, Crouse LC, Wallace SM, Carroll EE. Peri-pubertal administration of 3-nitro-1,2,4-triazol-5-one (NTO) affects reproductive organ development in male but not female Sprague Dawley rats. Reprod Toxicol. 2015;57:1-9.

12. Lent EM, Crouse LC, Jackovitz AM, Carroll EE, Johnson MS. An extended one-generation reproductive toxicity test of 1,2,4-Triazol-5-one (NTO) in rats. J Toxicol Environ Health A. 2016b;18:1-20.

13. Mullins $\mathrm{AB}$, Despain $\mathrm{KE}$, Wallace $\mathrm{SM}$, Honnold $\mathrm{CL}$, Lent EM. Testicular effects of 3-nitro-1,2,4-triazol-5-one (NTO) in mice when exposed orally. Toxicol Mech Methods. 2016;26(2):97-103.

14. Quinn MJJ, Bannon DI, Jackovitz AM, Hanna TL, Shiflett AA, Johnson MS Assessment of 3-nitro-1,2,4-triazol-5-one as a potential endocrine disrupting chemical in rats using the Hershberger and uterotrophic bioassays. Int J Toxicol. 2014:33(5):367-72.

15. Reddy G, Song J, Kirby P, Lent EM, Crouse LC, Johnson MS. Genotoxicity assessment of an energetic propellant compound, 3-nitro-1,2,4-triazol-5-one (NTO). Mutat Res. 2011;719(1-2):35-40.

16. Sarlauskas J, Nemeikaite-Ceniene A, Anusevicius Z, Miseviciene L, Maroziene A, Markevicius A, Cenas N. Enzymatic redox properties of novel nitrotriazole explosives implications for their toxicity. Z Naturforsch C. 2004:59(5-6):399-404

17. Liang J, Olivares C, Field JA, Sierra-Alvarez R. Microbial toxicity of the insensitive munitions compound, 2,4-dinitroanisole (DNAN), and its aromatic amine metabolites. J Hazard Mater. 2013;262:281-7.

18. Dodard SG, Sarrazin M, Hawari J, Paquet L, Ampleman G, Thiboutot S, Sunahara Gl. Ecotoxicological assessment of a high energetic and insensitive munitions compound: 2,4-dinitroanisole (DNAN). J Hazard Mater. 2013:262:143-50.

19. Prasath A, Panneerselvan L, Provatas A, Naidu R, Megharaj M. Genotoxicity assessment of acute exposure of 2, 4-dinitroanisole, its metabolites and 2,4, 6-trinitrotoluene to Daphnia carinata. Ecotoxicology. 2016;25(10):1873-9.

20. Kennedy AJ, Laird JG, Lounds C, Gong P, Barker ND, Brasfield SM, Russell AL, Johnson MS. Inter- and intraspecies chemical sensitivity: a case study using 2,4-dinitroanisole. Environ Toxicol Chem. 2015;34(2):402-11.

21. Stanley JK, Lotufo GR, Biedenbach JM, Chappell P, Gust KA. Toxicity of the conventional energetics TNT and RDX relative to new insensitive munitions constituents DNAN and NTO in Rana pipiens tadpoles. Environ Toxicol Chem. 2015;34(4):873-9.

22. Van der Schalie $\mathbf{W H}$. The toxicity of nitroguanidine and photolyzed nitroguanidine to freshwater aquatic organisms. Frederick: U.S. Army Medical Bioengineering Research and Development Laboratory Technical Report 8404, U.S. Army Medical Research and Development Command, Fort Detrick; 1985.

23. Burton DT, Turley SD, Peters GT. Toxicity of nitroguanidine, nitroglycerin, hexahydro-1,3,5-trinitro-1,3,5-triazine (RDX), and 2,4,6-trinitrotoluene (TNT) to selected freshwater aquatic organisms. Frederick: U.S. Army Biomedical Research and Development Laboratory Final Report WREC-93-B3, U.S. Army Medical Research and Development Command, Fort Detrick; 1993.

24. Gust KA, Lotufo GR, Stanley JK, Wilbanks MS, Chappell PS, Barker ND. Transcriptomics provides mechanistic indicators of mixture toxicology for IMX-101 and IMX-104 formulations in fathead minnows (Pimephales promelas). Aquat Toxicol. 2018;199:138-51.

25. Gust KA, Stanley JK, Wilbanks MS, Mayo ML, Chappell P, Jordan SM, Moores LC, Kennedy AJ, Barker N. The increased toxicity of UV-degraded nitroguanidine and IMX-101 to zebrafish larvae: evidence implicating oxidative stress. Aquat Toxicol. 2017;190:228-45.

26. Hunt PR. The C. elegans model in toxicity testing. J Appl Toxicol. 2017; 37(1):50-9.

27. Altun ZF, Hall DH. Handbook of C. elegans Anatomy. In: WormAtlas; 2018. Retrieved at http://www.wormatlas.org/hermaphrodite/ hermaphroditehomepage.htm on October 20, 2018.

28. C. elegans Sequencing Consortium. Genome sequence of the nematode $C$. elegans: a platform for investigating biology. Science. 1998;282(5396):2012-8.

29. Leung MC, Williams PL, Benedetto A, Au C, Helmcke K, Aschner M, Meyer $J$ N. Caenorhabditis elegans: an emerging model in biomedical and environmental toxicology. Toxicol Sci. 2008;106(1):5-28.

30. de Voer G, Peters D, Taschner PE. Caenorhabditis elegans as a model for lysosomal storage disorders. Biochim Biophys Acta. 2008;1782:433-46.

31. Roh HC, Collier S, Guthrie J, Robertson JD, Kornfeld K. Lysosome-related organelles in intestinal cells are a zinc storage site in C. elegans. Cell Metab. 2012;15:88-99

32. Williams PL, Dusenbery DB. Using the nematode Caenorhabditis elegans to predict mammalian acute lethality to metallic salts. Toxicol Ind Health. 1988; 4:469-78.

33. Hunt PR, Olejnik N, Sprando RL. Toxicity ranking of heavy metals with screening method using adult Caenorhabditis elegans and propidium iodide replicates toxicity ranking in rat. Food Chem Toxicol. 2012;50:3280-90.

34. Brenner S. The genetics of Caenorhabditis elegans. Genetics. 1974;77:71-94.

35. Stiernagle T. Maintenance of C. elegans. In: Ambros V, editor. WormMethods, section Basic Methods for C. elegans; 2006. Retrieved at http://www. wormbook.org/chapters/www_strainmaintain/strainmaintain.html on December 6, 2017.

36. Porta-de-la-Riva M, Fontrodona L, Villanueva A, Cerón J. Basic Caenorhabditis elegans methods: synchronization and observation. J Vis Exp. 2012;(64):e4019. https://www.ncbi.nlm.nih.gov/pubmed/22710399.

37. Donkin SG, Williams PL. Influence of developmental stage, salts, and food presence on various end points using Caenorhabditis elegans for aquatic toxicity testing. Environ Toxicol Chem. 1995;14(12):2139-47.

38. Khanna N, Cressman CP II, Tatara CP, Williams PL. Tolerance of the nematode Caenorhabditis elegans to $\mathrm{pH}$, salinity, and hardness in aquatic media. Arch Environ Contam Toxicol. 1997:32:110-44.

39. Gong P, Guan X, Pirooznia M, Liang C, Perkins EJ. Gene expression analysis of $C L$-20-induced reversible neurotoxicity reveals $G A B A_{A}$ receptors as potential targets in the earthworm Eisenia fetida. Environ Sci Technol. 2012:46(2):1223-32.

40. Wright GW, Simon RM. A random variance model for detection of differential gene expression in small microarray experiments. Bioinformatics. 2003;19(18):2448-55 
41. Fabregat A, Sidiropoulos K, Garapati P, Gillespie M, Hausmann K, Haw R, Jassal B, Jupe S, Korninger F, McKay S, Matthews L, May B, Milacic M, Rothfels K, Shamovsky V, Webber M, Weiser J, Williams M, Wu G, Stein L, Hermjakob H, D'Eustachio P. The Reactome pathway knowledgebase. Nucleic Acids Res. 2016;44(D1):D481-7.

42. Subramanian A, Tamayo P, Mootha VK, Mukherjee S, Ebert BL, Gillette MA, Paulovich A, Pomeroy SL, Golub TR, Lander ES, Mesirov JP. Gene set enrichment analysis: a knowledge-based approach for interpreting genomewide expression profiles. Proc Natl Acad Sci U S A. 2005;102(43):15545-50.

43. Kanehisa M, Furumichi M, Tanabe M, Sato Y, Morishima K. KEGG: new perspectives on genomes, pathways, diseases and drugs. Nucleic Acids Res. 2017;45(D1):D353-61.

44. Harizi H, Corcuff J-B, Gualde N. Arachidonic-acid-derived eicosanoids: roles in biology and immunopathology. Trends Mol Med. 2008;14(10):461-9.

45. Buczynski MW, Dumlao DS, Dennis EA. Thematic review series: proteomics. An integrated omics analysis of eicosanoid biology. J Lipid Res. 2009;50(6): 1015-38.

46. Guengerich FP. Cytochrome P450s and other enzymes in drug metabolism and toxicity. AAPS J. 2006;8(1):E101-11.

47. Gong P, Perkins EJ. Earthworm toxicogenomics: a renewed genome-wide quest for novel biomarkers and mechanistic insights. Appl Soil Ecol. 2016; 104:12-24.

48. Gong P, Guan X, Inouye LS, Pirooznia M, Indest KJ, Athow RS, Deng Y, Perkins EJ. Toxicogenomic analysis provides new insights into molecular mechanisms of the sublethal toxicity of 2,4,6-trinitrotoluene in Eisenia fetida. Environ Sci Technol. 2007a;41(23):8195-202.

49. Gong P, Guan X, Inouye LS, Deng Y, Pirooznia M, Perkins EJ. Transcriptomic analysis of RDX and TNT interactive sublethal effects in the earthworm Eisenia fetida. BMC Genomics. 2008;9(Suppl 1):S15.

50. Li Y, Wang N, Perkins EJ, Zhang C, Gong P. Identification and optimization of classifier genes from multi-class earthworm microarray dataset. PLoS One. 2010;5(10):e13715.

51. Nan X, Wang N, Gong P, Zhang C, Chen Y, Wilkins D. Biomarker discovery using 1-norm regularization for multi-class earthworm microarray gene expression data. Neurocomputing. 2012;92:36-43.

52. Yang Y, Li S, Maxwell AS, Barker ND, Peng Y, Li Y, Li H, Wu X, Li P, Huang T, Zhang C-H, Wang N, Perkins EJ, Zhang C-Y, Gong P. Deciphering chemically-induced reversible neurotoxicity by reconstructing perturbed pathways from time series microarray gene expression data, Proceedings of 2013 IEEE International Workshop on Genomic Signal Processing and Statistics (GENSIPS 2013, ISBN: 978-1-4799-3462-1); 2013. p. 45-8.

53. Gong P, Inouye LS, Perkins EJ. Comparative neurotoxicity of two energetic compounds, hexanitrohexaazaisowurtzitane and hexahydro-1,3,5-trinitro1,3,5-triazine, in the earthworm Eisenia fetida. Environ Toxicol Chem. 2007b;26(5):954-9.

54. Olivares Cl, Sierra-Alvarez R, Abrell L, Chorover J, Simonich M, Tanguay RL, Field JA. Zebrafish embryo toxicity of anaerobic biotransformation products from the insensitive munitions compound 2,4-dinitroanisole. Environ Toxicol Chem. 2016a;35(11):2774-81.

55. Olivares Cl, Sierra-Alvarez R, Alvarez-Nieto C, Abrell L, Chorover J, Field JA. Microbial toxicity and characterization of DNAN (bio)transformation product mixtures. Chemosphere. 2016b;154:499-506.

56. Madeira CL, Field JA, Simonich MT, Tanguay RL, Choroverc J, Sierra-Alvarez R. Ecotoxicity of the insensitive munitions compound 3-nitro-1,2,4-triazol-5one (NTO) and its reduced metabolite 3-amino-1,2,4-triazol-5-one (ATO). J Hazard Mater. 2018;343:340-6.

57. Liao C, Gock A, Michie M, Morton B, Anderson A, Trowell S. Behavioural and genetic evidence for $C$. elegans' ability to detect volatile chemicals associated with explosives. PLoS One. 2010;5(9):e12615.

58. Bargmann $\mathrm{Cl}$, Hartwieg E, Horvitz HR. Odorant-selective genes and neurons mediate olfaction in C. elegans. Cell. 1993;74:515-27.

Ready to submit your research? Choose BMC and benefit from:

- fast, convenient online submission

- thorough peer review by experienced researchers in your field

- rapid publication on acceptance

- support for research data, including large and complex data types

- gold Open Access which fosters wider collaboration and increased citations

- maximum visibility for your research: over $100 \mathrm{M}$ website views per year

At BMC, research is always in progress.

Learn more biomedcentral.com/submissions 